\title{
Seasonal incidence of lameness and risk factors associated with thin soles, white line disease, ulcers, and sole punctures in dairy cattle
}

\author{
A. H. Sanders, * J. K. Shearer, $†$ and A. De Vries* \\ *Department of Animal Sciences, and \\ †Department of Large Animal Clinical Sciences, University of Florida, Gainesville 32611
}

\begin{abstract}
Lameness is a multifactorial condition with many causes. In this study, cow lifetime records were used to quantify the incidence of specific lameness-causing lesions and investigate factors associated with those lesions. Of primary interest were the effects of seasonality and the effects of thin soles (TS). Thin sole-induced toe ulcers (TSTU) occurring adjacent to the white line in the apical portion of the weight-bearing surface were distinguished from white line disease (WLD) occurring in the region of the abaxial heel sole junction. Sole (SU), heel (HU), and toe (TU) ulcers; TS; sole punctures (SP); leg injuries (INJ); and other (OTH) lesions (e.g., infectious diseases, laminitis, unclassified hemorrhage) were also considered. Data were collected from May 2004 through October 2007 and included records for 4,915 cows of which 1,861 had at least one recorded lameness event. Of these, $20 \%$ were TSTU, $20 \%$ OTH, $16 \%$ SU, $13 \%$ TS, $10 \%$ WLD, $8 \%$ HU, $6 \%$ INJ, $4 \% \mathrm{SP}$, and $2 \%$ TU. Annual incidence risk for lameness was $49.1 \%$. Overall incidence rate for lameness was 1.41/1,000 cow-days, and rates for all lesions were highest in the summer. As parity increased, so did incidence rates for TS, SU, WLD, HU, and INJ. For TS, TSTU, and WLD, incidence rates were lowest in early lactation (16 to $60 \mathrm{DIM}$ ), whereas for SU, $\mathrm{HU}, \mathrm{TU}$, incidence rates were highest in mid lactation (61 to 150 DIM). Cox proportional hazard models for TS, TSTU, WLD, SU, HU, TU, and SP included age and year of first calving and milk production capacity. Prior/concurrent lameness events, season, parity, and stage of lactation were included as time-dependent effects. Prior/concurrent TS increased the hazard for all other lesions, particularly TSTU, and HU. Having any other prior claw lesion also increased the hazard for all lesions. Hazard was highest in summer for all lesions except TU. Stage of lactation was a significant effect
\end{abstract}

Received October 9, 2008.

Accepted March 16, 2009.

${ }^{1}$ Corresponding author: devries@ufl.edu in hazard of TSTU, which was lowest in mid lactation (61 to 150 DIM).

Key words: lameness, risk factor, claw lesion

\section{INTRODUCTION}

Lameness is a leading health and economic problem in the dairy industry (Kossaibati and Esslemont, 1997). Besides the direct costs of treatment, lameness negatively affects milk production (Warnick et al., 2001; Amory et al., 2008) and reproduction (Barkema et al., 1994; Hernandez et al., 2001), and increases culling (Booth et al., 2004). Prevalence of lameness in US cows in commercial freestall housing is approximately $25 \%$ (Cook, 2003; Espejo et al., 2006), but varies greatly from farm to farm. Kelton et al. (1998) reported a median lactational incidence risk of $7 \%$ with a range from 1.8 to $30 \%$ based on 39 citations. Part of the high variability of incidence of lameness in these reports is due to the lack of standard case definitions (Green et al., 2002). Dairy producers tend to underestimate the prevalence and incidence of lameness compared with trained investigators (Wells et al., 1993).

Lameness is a multifactorial condition. Primary causes include infectious agents (e.g., foot rot), laminitis, conformational or other lesions (e.g., corkscrew claw, leg injury); and claw lesions such as white line disease (WLD), thin sole-induced toe ulcers (TSTU), sole ulcers (SU), heel ulcers (HU), toe ulcers (TU), sole punctures (SP), and thin soles (TS). Cow risk factors associated with lameness are diet (Amory et al., 2006; Cook and Nordlund, 2009), high milk production (Green et al., 2002; Amory et al., 2008), and underconditioning (Espejo et al., 2006). Environmental factors such as housing type, stall surface, and season also affect the prevalence of lameness (Cook, 2003).

Few studies have reported on the incidence and risk factors of claw lesion-specific causes of lameness. Diagnosis of lameness is generally based on gait abnormalities, but definitions vary and identification of specific causes is inconsistent. Furthermore, the available studies differ in the types of diagnoses that are reported. Amory et al. (2008) reported mean incidence rates of $0.18,0.14$, 
0.17 , and 0.15 per 1,000 cow-days for SU, WLD, digital dermatitis, and other causes of lameness, respectively, for 1,824 dairy cows on 30 farms in England and Wales in 2003 to 2004. Also in the United Kingdom, Laven and Lawrence (2006) reported on 48,720 cases of lameness collected through veterinary practitioners. Of all reported lameness cases, WLD accounted for $15.5 \%$ and SU accounted for $15.9 \%$. Other common diseases were digital dermatitis (6.7\%) and foul-in-the-foot (6.2\%). Seasonality in the incidence of WLD and SU was not apparent. Barkema et al. (1994) reported that 31.5\% of 637 first diagnoses in Dutch dairy cows were SU. Six other diagnoses were also reported. In the United States, results from 2 New York dairy farms in 1997 and 1998 showed that 20.1 and $17.4 \%$ of cows reported as lame were diagnosed with SU (Warnick et al., 2001). These authors reported 9 other diagnoses.

The white line is the junction between the wall and sole horn of the bovine claw. The white line may become a point of entry for foreign material, which can result in WLD and lameness. Compression of the corium between the sole and third phalange can result from overtrimming or inflammation and rotation of the phalange due to laminitis. This compression can cause the formation of ulcers in the apical region of the sole (i.e., TU). Lameness caused by TSTU is commonly misdiagnosed as WLD or TU. On closer inspection, these lesions are actually observed to be a consequence of thinning of the sole resulting in a break or separation of the sole away from the white line (van Amstel and Shearer, 2008). These lesions are typically found in the apical portion of the sole adjacent to the abaxial white line. Before separation occurs, these lesions are typically hemorrhagic. Once the underlying corium is exposed a subsolar abscess will develop, and affected animals become very lame.

Toussaint Raven (1989) established $7 \mathrm{~mm}$ as the minimum adequate sole thickness to provide protection to the claw capsule. Sole thickness is a function of the rate of growth versus the rate of wear. Increased moisture has been associated with TS (van Amstel et al., 2004). Moisture leads to increased wear, and thin-soled claws absorb more moisture, thus TS may be a selfperpetuating condition. Lameness is observed with TS as the primary diagnosis, but TS has also been associated with subsequent vascular injury, primarily sole/ white line separation (i.e., TSTU) and SU (van Amstel et al., 2004). Compared with the conditions in previous studies in Europe (Barkema et al., 1994; Amory et al., 2006; Laven and Lawrence, 2006), and the northern United States (Warnick et al., 2001), cows in the southeastern United States are exposed to extremely moist conditions, particularly during the summer, because of the humidity and cow cooling systems. The differ- ent seasonal pattern of environmental moisture would be expected to result in different seasonal patterns of lameness if moisture is a significant factor.

Treatment rather than prevention is the focus of many lameness management programs. Treatment options for TS are limited, thus this condition has received less attention than other lesions. When TS is reported, it may be associated with subsequent diagnosis of an ulcerative condition such as SU or TSTU. The objectives of this study were to 1) quantify the incidence of specific, noninfectious, lameness-causing lesions; and 2) investigate factors associated with those lesions. Particularly, TSTU is evaluated as a lesion distinct from WLD or SU, and TS is considered as a predisposing factor for other claw lesions.

\section{MATERIALS AND METHODS}

\section{Data}

Data were DHIA lactation records and lameness treatment records from a 2,100-cow dairy in the southeastern United States, collected between May 2004 and October 2007. Cows were fed a TMR and milked twice daily. Housing was in sand-bedded freestalls. Fans and low-pressure foggers were used for cooling. Some cows had access to dirt lots, weather permitting. Average daily low/high temperatures in this region range from $3 / 17^{\circ} \mathrm{C}$ in January to $21 / 33^{\circ} \mathrm{C}$ in July. Relative humidity is highest in August when the morning to afternoon range is approximately 60 to $93 \%$. Afternoon humidity is always high, climbing to $>85 \%$ at any time of year; however, from February through May, morning humidity generally falls to approximately $50 \%$. Most travel lanes and feed alleys had rubber belting. Manure in the alleys was removed by a water flush system. Portions of travel lanes from the freestalls to the parlor holding area were grooved concrete. Cows were observed for lameness daily by trained farm workers as they entered the parlor holding area.

Lactating cows identified as lame were presented to 1 of 2 claw trimmers certified through the Master Hoof Care Program (University of Florida) and employed full-time on this farm during the data collection period. Claw lesions were recorded using the system reported by the American Association of Bovine Practitioners (Shearer et al., 2004). Trimmers with similar training in this system were shown to have almost perfect agreement on lesion identification quizzes (Cramer et al., 2008). Lesions recorded included TSTU in claw zones 1 and 2 (Figure 1); WLD in zone 3; SU in zone 4, TU in zone 5 , or HU in zone 6 ; and TS, SP, and INJ (not zone specific). Digital dermatitis, acute laminitis, unclassified sole hemorrhage, and miscellaneous lesions 
(e.g., corkscrew claw) were grouped as other (OTH) for the purposes of this analysis (not zone specific). Approximately half of these were digital dermatitis.

Routine trimming was performed on all cows at approximately 150 DIM and at dry off. It was considered whether lesions recorded in cows not presented for lameness (but for routine trimming) would result in bias at these times. No evidence of increased reporting of any lesion was found. This also suggests that most lesions of interest were discovered in a timely way through the daily observation for lameness. Cows with lameness during the dry period were rare (75 cows). Dry cows were not observed daily, nor were diagnosis dates recorded for those found lame. Consequently, all records for these cows were omitted from the study. Of 4,915 cows with lactation records, 1,861 had at least one lesion recorded by the trimmer. Every occurrence recorded was counted as a separate event. Records did not indicate which foot was affected.

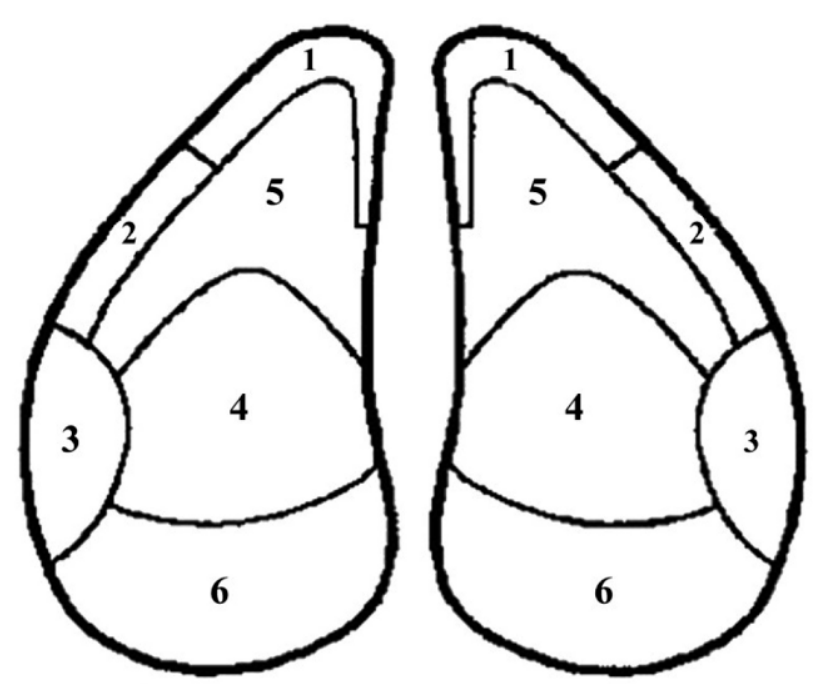

\begin{tabular}{ll}
\hline Recorded lesion & Claw zone \\
\hline Thin sole toe ulcers (TSTU) & 1 and 2 \\
White line disease (WLD) & 3 \\
Sole ulcers (SU) & 4 \\
Toe ulcers (TU) & 5 \\
Heel ulcers (HU) & 6 \\
Thin soles (TS) & none \\
Sole puncture (SP) & none \\
Injuries (INJ) & none \\
Other (OTH) & none \\
\hline
\end{tabular}

Figure 1. Claw diagram showing claw zones used in recording lameness-causing lesions. Adapted from Shearer et al. (2004).

\section{Statistical Analysis}

Table 1 shows numbers of claw lesions recorded and the average numbers of lactating cows by year and season. Incidence risks were calculated as the number of new cases of a claw lesion in a defined period given the number of animals at risk (Dohoo et al., 2003). For example, 179 cases of TS were recorded in 2006 and the average herd size that year was 2,166 ; thus, the annual incidence risk of a case of TS during 2006 is 179/2,166 $=8.3 \%$. Annual incidence risks were estimated as the sum of calculated seasonal incidence risks assuming an average number of cows at risk. Incidence risks are sometimes referred to as cumulative incidence and are more common in the literature than incidence rates.

Incidence rates for TS, TSTU, SU, WLD, HU, INJ, $\mathrm{SP}, \mathrm{TU}$, and OTH were calculated by season, parity, stage of lactation, and overall as the number of new cases of a claw lesion per 1,000 cow-days (Dohoo et al., 2003). For instance, in the above example, the lactation records for 2006 included 790,702 cow-days (a cow in the herd and milking for the entire year, would contribute 365 cow-days); thus, incidence rate $=179 / 790,702$ $\times 1,000=0.23 / 1,000$ cow-days. Lactation records were not available for part of 2007, which made an accurate enumeration of cow-days during the study period of that year impossible. Thus, incidence rates were calculated using data from 2004 through 2006.

Kaplan-Meier (KM) survival distribution functions (SDF) for TS, TSTU, SU, WLD, HU, INJ, SP, and TU were estimated using the LIFETEST procedure of SAS (SAS Institute, 2005). Records started with first calving and continued until the first occurrence of the claw lesion of interest, culling, or the end of the study period (October 2007). Entry into the risk pool was at time of first calving. Because no lameness records are available from before May 2004, the survival data set was restricted to cows having a first calving since May 2004. The survival data set included records for 2,672 cows, of which 799 had at least one lesion recorded by the trimmer.

Seven separate Cox proportional hazards models were used to evaluate risk factors for first lifetime occurrences of TS, TSTU, SU, WLD, HU, SP, and TU. Effects considered were age at first calving, year of first calving, milk production capacity, parity, season, stage of lactation, prior cases of TS, and prior cases of other claw lesions (OCL) except the lesion of interest. For example, in the model for TSTU, prior cases of SU, WLD, HU, SP, and TU were grouped in the OCL category. Because the primary interest was in TS as a predisposing factor for OCL, its prior effect was included separately. Cows were not observed daily for lameness during the dry period, thus they had essen- 
Table 1. Numbers of recorded claw lesions and average numbers of lactating cows (herd size), by year and season

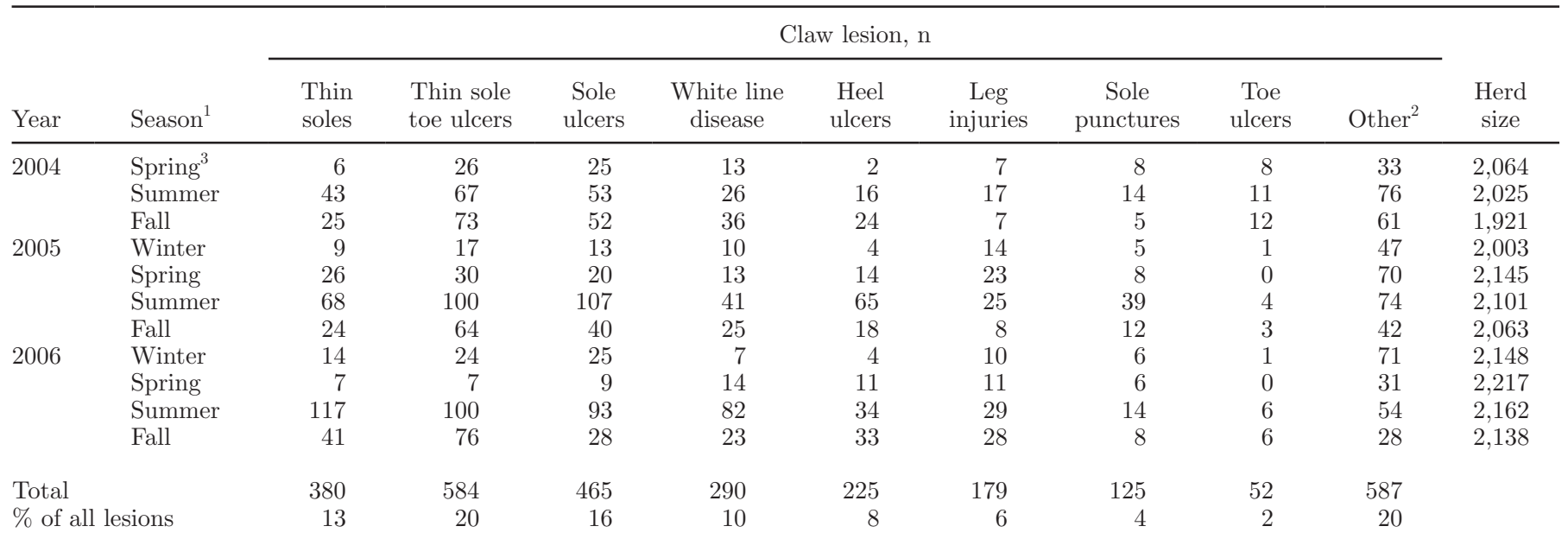

${ }^{1}$ Four 3-mo seasons: January through March was considered winter.

${ }^{2}$ Other reported lesions included infectious diseases, laminitis, and mechanical claw defects.

${ }^{3}$ Spring 2004 data are from May and June only.

tially no opportunity to be diagnosed lame during this time. Accordingly, cows were not considered to be at risk during the dry period (i.e., they were temporarily removed from the risk set). The potential for interval censoring (cows that became lame during the dry period and were diagnosed at calving) was ignored. However, $<1 \%$ of all lesions were reported within the first $2 \mathrm{~d}$ of calving when cows returned to daily observation.

The effects for prior TS and prior OCL were treated as time-dependent (Allison, 1995), considered in 6 possible states based on how recently a prior case had taken place (no prior case; concurrent case with the claw lesion of interest; and cases 1 to $30 \mathrm{~d}, 31$ to $60 \mathrm{~d}$, 61 to $180 \mathrm{~d}$, and $>180 \mathrm{~d}$ before the end of the record. Parity $(1,2, \geq 3)$, season (3 mo each; January through March was considered winter), and stage of lactation ( 1 to 14,15 to 59,60 to 149,150 to 240,241 to 305 , and $>305$ DIM) were also treated as time-dependent effects.

Milk production capacity, age at first calving, and year of enrollment were not time-dependent. Numbers of uncensored records and those having prior or concurrent lesions for each model are in Table 2. Available milk production records would not support evaluation of causative relationships between daily production and lameness. An estimate of milk production capacity was used to account for possible difference in the relative production of cows that became lame. The DHIA lactation record includes an estimate of expected 305d production, which includes actual production data adjusted for age, parity, and season of calving (305-d mature equivalent). The average deviation of individual records from the herd mean, by parity, was used to represent the relative milk production capacity for each cow. These ranged from $-3,057 \mathrm{~kg}$ for the lowest producing cow to $3,025 \mathrm{~kg}$ for the highest producing cow.

Model building occurred in 2 steps. First, univariate models were evaluated using the PHREG procedure of SAS to identify the non-time-dependent effects likely to have significant effects in multivariate models. Linear and quadratic effects were considered, and those having a $P$-value for $\chi^{2}<0.25$ were included in later models.

Table 2. Numbers of lifetime records including an occurrence of a specific lesion and those also including a prior occurrence of thin soles (TS) or other claw lesion (OCL) in the survival data set

\begin{tabular}{lccccc}
\hline Lesion & $\begin{array}{c}\text { Total } \\
\text { records }\end{array}$ & $\begin{array}{c}\text { Prior } \\
\text { TS }\end{array}$ & $\begin{array}{c}\text { Concurrent } \\
\text { TS }\end{array}$ & $\begin{array}{c}\text { Prior } \\
\text { OCL }\end{array}$ & $\begin{array}{c}\text { Concurrent } \\
\text { OCL }\end{array}$ \\
\hline Thin soles & 265 & - & - & 48 & 33 \\
Thin sole toe ulcers & 243 & 30 & 13 & 34 & 11 \\
Sole ulcers & 166 & 12 & 10 & 16 & 18 \\
White line disease & 94 & 6 & 7 & 20 & 7 \\
Heel ulcers & 70 & 12 & 5 & 17 & 1 \\
Sole punctures & 81 & 3 & 1 & 4 & 2 \\
Toe ulcers & 27 & 1 & 2 & & \\
\hline
\end{tabular}


RISK OF DIAGNOSIS-SPECIFIC LAMENESS

Table 3. Incidence rates per 1,000 cow-days for lesions by season, parity, and stage of lactation

\begin{tabular}{|c|c|c|c|c|c|c|c|c|c|c|}
\hline Cohort & $\begin{array}{l}\text { Thin } \\
\text { soles }\end{array}$ & $\begin{array}{l}\text { Thin sole } \\
\text { toe ulcers }\end{array}$ & $\begin{array}{l}\text { Sole } \\
\text { ulcers }\end{array}$ & $\begin{array}{c}\text { White line } \\
\text { disease }\end{array}$ & $\begin{array}{l}\text { Heel } \\
\text { ulcers }\end{array}$ & $\begin{array}{c}\text { Leg } \\
\text { injuries }\end{array}$ & $\begin{array}{c}\text { Sole } \\
\text { puncture }\end{array}$ & $\begin{array}{l}\text { Toe } \\
\text { ulcer }\end{array}$ & Other & All \\
\hline Winter (Jan-Mar) & 0.06 & 0.11 & 0.10 & 0.05 & 0.02 & 0.06 & 0.03 & 0.01 & 0.32 & 0.75 \\
\hline Spring (Apr-Jun) & 0.07 & 0.12 & 0.10 & 0.08 & 0.05 & 0.08 & 0.04 & 0.02 & 0.26 & 0.81 \\
\hline Fall (Oct-Dec) & 0.16 & 0.38 & 0.21 & 0.15 & 0.13 & 0.08 & 0.04 & 0.04 & 0.23 & 1.42 \\
\hline First parity & 0.15 & 0.31 & 0.16 & 0.09 & 0.06 & 0.05 & 0.06 & 0.03 & 0.18 & 1.09 \\
\hline 1 to 15 DIM & 0.20 & 0.37 & 0.21 & 0.21 & 0.13 & 0.11 & 0.05 & 0.01 & 0.35 & 1.64 \\
\hline 16 to $60 \mathrm{DIM}$ & 0.14 & 0.20 & 0.17 & 0.09 & 0.11 & 0.09 & 0.04 & 0.03 & 0.24 & 1.12 \\
\hline 61 to 150 DIM & 0.15 & 0.23 & 0.32 & 0.11 & 0.17 & 0.07 & 0.08 & 0.04 & 0.28 & 1.45 \\
\hline 151 to 240 DIM & 0.16 & 0.28 & 0.24 & 0.12 & 0.08 & 0.08 & 0.06 & 0.02 & 0.26 & 1.31 \\
\hline 241 to 305 DIM & 0.19 & 0.38 & 0.20 & 0.19 & 0.12 & 0.10 & 0.08 & 0.03 & 0.25 & 1.54 \\
\hline$>305$ DIM & 0.26 & 0.32 & 0.18 & 0.18 & 0.08 & 0.10 & 0.04 & 0.02 & 0.35 & 1.51 \\
\hline
\end{tabular}

In the second step, full models including all timedependent effects and the non-time-dependent effects identified through univariate screening were analyzed using the PHREG procedure. Effects with $P$-values for $\chi^{2}>0.10$ for all categories were removed from the full models. The Schwarz-Bayesian criteria indicated improved fit from inclusion of effects and model reduction for all final models.

To investigate possible changes in hazard over time, the GENMOD procedure of SAS was used to analyze the 7 survival models, using the complementary log-log function (Allison, 1995). The same effects defined for the final proportional hazards models were included, with the addition of time at risk. Unrestricted (i.e., Cox), Gompertz, and Weibull models for the effect of time were considered. Estimates for the effects of day of risk were transformed to hazard estimates by the formula $\exp (\mu+\alpha)$, where $\mu$ is the intercept and $\alpha$ is the coefficient for the given day of risk.

\section{RESULTS}

\section{Incidences}

The overall annual incidence risk for lameness was 49.1\%. For individual lesions, annual incidence risks were $6.3 \%$ for TS, $9.8 \%$ for TSTU, $7.8 \%$ for SU, $4.8 \%$ for WLD, $3.7 \%$ for HU, 3.1\% for INJ, $2.1 \%$ for SP, and $0.9 \%$ for TU. Of all reported claw lesions, $20 \%$ were TSTU, $20 \% \mathrm{OTH}, 16 \% \mathrm{SU}, 13 \% \mathrm{TS}$, and $10 \% \mathrm{WLD}$ (Table 1).

Overall incidence rate of lameness was 1.41/1,000 cow-days. Table 3 includes incidence rates by season, parity, stage of lactation, and overall. For all individual lesions considered, incidence rates were greatest in the summer and lowest in the winter. The greatest seasonal effects were seen for HU and TS.
Greater parity was associated with increased incidence rates for TS, SU, WLD, HU, and INJ, but not for TSTU, SP, or TU. In all stages of lactation, TSTU had the highest incidence rates compared with the other claw lesions. For SU, HU, and TU, incidence rates were greatest in mid lactation (61 to $150 \mathrm{DIM}$ ). In the first 15 DIM, TS, TSTU, and WLD were at or near their greatest rates, but were at their lowest rates from 16 to 60 DIM.

\section{Survival Analysis}

The SDF from time of first calving to first occurrence of claw lesions are shown in Figure 2. The negative slope was greatest for TS, TSTU, and SU, which is in agreement with Table 3 (i.e., these lesions had the greatest incidence rates). All SDF were approximately linear except that for $\mathrm{SU}$, which had a greater rate than any other lesions in the first $200 \mathrm{~d}$, but a rate similar to that of WLD, HU, SP, and INJ thereafter. The loss of cows from the risk set over time is reflected by the increase in the KM error. The number of surviving cows (of the total 2,767) and the $95 \%$ confidence intervals for KM estimates for 100, 300, 500, and 1,000 d from first calving are included in Table 4 . Overall, $50 \%$ of the cows at risk remained in the herd until at least $430 \mathrm{~d}$ after first calving.

The final multivariate Cox proportional hazards regression results are presented in Table 5 (TS), 6 (TSTU, SU, WLD), and 7 (HU, SP, TU). For all lesions except TU, hazard (i.e., risk) was greatest in the summer. The hazard for TU was greatest in the fall. Second greatest hazards were found in the fall and the lowest in the winter. These results correspond with the seasonal incidence rates shown in Table 3. Tables 5, 6 , and 7 show that seasonal differences were greatest for TS, WLD, and HU. 
Table 4. Kaplan-Meier 95\% confidence intervals (\%) for survival estimates at 100, 300, 500, and 1,000 d since first calving $(\mathrm{n}=2,676)$, by lesion, and cows remaining at risk

\begin{tabular}{|c|c|c|c|c|}
\hline \multirow[b]{2}{*}{ Lesion } & \multicolumn{4}{|c|}{ Days since first calving } \\
\hline & 100 & 300 & 500 & 1,000 \\
\hline Thin soles & $97.8-98.8$ & $92.9-94.9$ & $90.0-92.6$ & $73.3-79.9$ \\
\hline Thin sole toe ulcers & $96.5-97.8$ & $92.3-94.4$ & $89.4-92.1$ & $79.3-84.7$ \\
\hline Sole ulcers & $96.5-97.9$ & $93.4-95.3$ & $92.4-94.6$ & $87.3-91.4$ \\
\hline White line disease & $99.3-99.8$ & $97.1-98.4$ & $95.0-96.9$ & $90.2-94.0$ \\
\hline Heel ulcer & $98.8-99.5$ & $97.0-98.2$ & $96.4-97.9$ & $94.5-96.9$ \\
\hline Injury & $98.8-99.5$ & $98.0-99.0$ & $96.6-98.1$ & $90.7-94.9$ \\
\hline Sole puncture & $98.8-99.5$ & $97.1-98.3$ & $96.3-97.8$ & $92.7-95.7$ \\
\hline Toe ulcer & $99.0-99.6$ & $98.6-99.4$ & $98.5-99.3$ & $97.6-99.2$ \\
\hline Surviving cows, $\mathrm{n}$ & 2,282 & 1,657 & 1,156 & 249 \\
\hline
\end{tabular}

Concurrent (case on same day as claw lesion) or recent prior cases of TS increased the hazard for all other lesions. A prior case of TS (up to $180 \mathrm{~d}$ ago) significantly increased hazards for TSTU (Table 6) and HU (Table 7), providing strong evidence that TS predisposes cows to TSTU and HU. For SU (Table 6), the hazard was greater when cows also had TS, but evidence that TS has a causal relationship with SU is not as strong. A prior case of TS was not associated with the risk of SP.
Stage of lactation was a significant factor in hazard for TSTU (Table 6), which was greatest just after calving (1 to 15 DIM) and lowest in mid lactation (61 to 150 DIM). For SU and WLD, hazard tended to decrease in later lactation. Hazard for TS (Table 5) increased with year of first calving. Year of first calving was not a significant effect for any other lesions considered.

Increased age at first calving decreased the hazard for TSTU and WLD (Table 6), but increased the hazard for HU (Table 7). The hazard for WLD (Table 6)

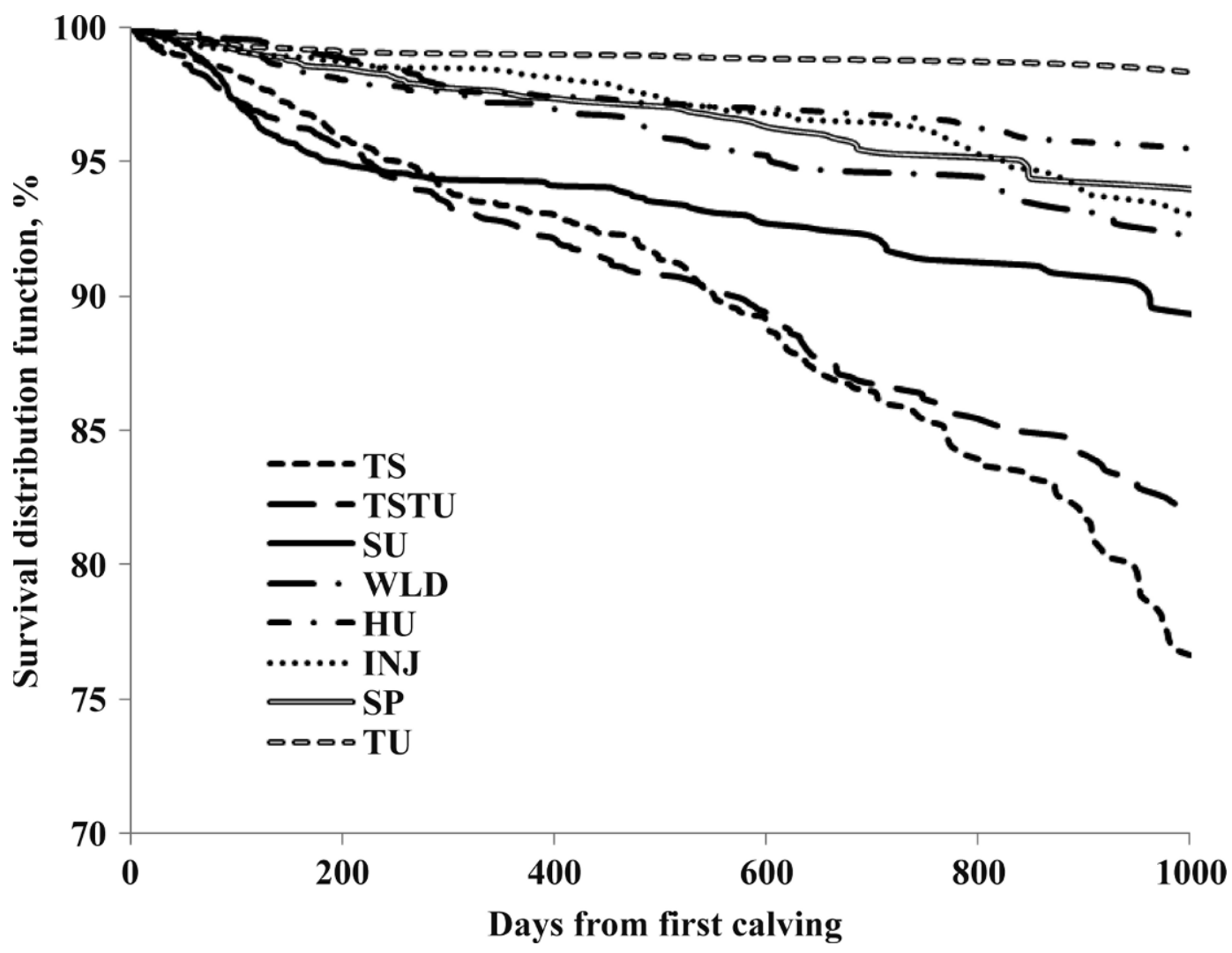

Figure 2. Kaplan-Meier survival distribution functions for time to first occurrence of thin soles (TS), thin sole toe ulcers (TSTU), sole ulcers (SU), white line disease (WLD), heel ulcers (HU), leg injuries (INJ), sole punctures (SP), and toe ulcers (TU). 
Table 5. Final multivariate Cox proportional hazards regression results for first occurrence of thin soles: hazard ratios (HR) with $95 \%$ confidence intervals (CI) for time-dependent effects [prior case of other claw lesions (OCL) and season] and parameter estimate (PE) for year of first calving

\begin{tabular}{lcc}
\hline & \multicolumn{2}{c}{ Thin soles } \\
\cline { 2 - 3 } Effect & HR & CI \\
\hline OCL (relative to none) & $38.84^{* * *}$ & $26.57-56.77$ \\
Concurrent & $2.81^{* * *}$ & $1.74-4.52$ \\
1 to 30 d ago & $2.53^{* *}$ & $1.29-4.96$ \\
31 to 60 d ago & 1.63 & $0.80-3.34$ \\
61 to 180 d ago & 0.89 & $0.48-1.67$ \\
$>180$ d ago & & \\
Season (relative to winter) & $1.77^{1 * *}$ & $0.73-3.99$ \\
Spring & $18.11^{* * *}$ & $8.86-37.02$ \\
Summer & $3.61^{* * *}$ & $1.71-7.64$ \\
Fall & & PE \\
& $0.46^{* * *}$ & 0.08 \\
\hline
\end{tabular}

${ }^{1}$ Four 3-mo seasons: January through March was considered winter. ** $P<0.01 ; * * * P<0.001$.

tended to be greater for cows with $\geq 3$ calvings. In this survival analysis model, parity is uncoupled from age or time since first calving; it is the number of calving events that have occurred by a given time at risk. In the case of WLD, for instance, a cow that has had 3 total calvings by $650 \mathrm{~d}$ after first calving will tend to have greater risk of WLD than the one that has had only 2 total calvings at 650 d after first calving, after accounting for the remaining effects in the model.

Concurrent or prior OCL increased hazards for TS, TSTU, WLD, and HU. Hazards for SU and TU were greater given a concurrent diagnosis of OCL compared with hazards when no OCL is recorded. Prior OCL did not result in increased hazards for SU and TU. Hazard for SP was increased for cows that had a diagnosis of OCL $>180$ d before SP compared with the hazard of $\mathrm{SP}$ when no OCL is recorded.

The GENMOD procedure was used to investigate changes in hazard over time by considering an unrestricted model including day at risk as a categorical variable (i.e., a Cox model). Only SU, TU, and TS had likelihood ratios showing significant differences from the reference period (before any events), indicating that the hazards for these lesions were not constant. Hazards for these lesions generally increased over time, although the hazard for SU appeared to peak in the first $200 \mathrm{~d}$ of first lactation.

\section{DISCUSSION}

\section{Incidences}

The overall annual incidence risk for lameness (49.1\%) observed in this study is consistent with previ- ous reports, although variation among herds can be considerable. Barkema et al. (1994) reported average lactational risks of $26 \%$ (13 herds ranged from 9.3 to $49.2 \%$ ) and Clarkson et al. (1996) reported average annual incidence of $54.6 \%$ (37 herds ranged from 10.7 to $170.1 \%)$. The annual incidence risks for specific lesions were generally as expected. The most commonly reported lesion was TSTU, which has not been considered in most previous studies.

Overall incidence rate of lameness $(1.41 / 1,000$ cowdays) was consistent with Clarkson et al. (1996) and Warnick et al. (2001), who reported incidence rates of 1.49 and 1.97/1,000 cow-days, respectively. The range of incidence rates was 0.27 to $4.93 / 1,000$ cow-days in those studies. The finding that incidence rates of all lesions investigated were greatest in the summer and lowest in the winter is contrary to results of previous studies in which lameness was more prevalent in winter (Cook, 2003; Espejo et al., 2006). Those studies were carried out in temperate climate conditions in Wisconsin and Minnesota where cow environments could be wetter in the winter. In the Wisconsin study, Cook (2003) notes a spike in the rate of lameness in September, which is attributed to heat stress in the prior months. In the United Kingdom, Laven and Lawrence (2006) reported that prevalence of WLD had shifted from being greatest in the winter to being greatest in summer. Their results may reflect an increase in yearround confinement housing in the United Kingdom that would increase exposure of claws to moisture during the summer. Increased standing time is associated with increased lameness (Cook et al., 2004) and this is also seasonal, depending on climate. Under conditions of heat stress, standing time increases (Cook et al., 2007); conversely, in temperate areas, winter conditions may increase standing time (Fregonesi et al., 2007).

\section{Survival Analysis}

The Cox proportional hazards regression results correspond with the seasonal incidence rates shown in Table 3 and are consistent with the apparent association between wet conditions and risk of lameness. Summers in the southeastern United States are hot and humid, and cow-cooling systems in use during the summer months create constantly wet conditions. It is possible that seasonal differences in metabolism because of changes in diet or heat stress are also factors.

Of major interest in the study was whether TS predispose cows for other lesions. The multi-fold increase in hazard for TSTU and HU attributed to prior TS in particular provide strong evidence that TS is a predisposing factor. A similar effect on SU and WLD is evident, but the association seen is not as strong. Borderas 
Table 6. Final multivariate Cox proportional hazards regression results for first occurrence of white line lesions, sole ulcers, and white line disease: hazard ratios (HR) with $95 \%$ confidence intervals (CI) for time-dependent effects [prior case of thin soles (TS) and other claw lesions (OCL), season, and stage of lactation] and parameter estimate (PE) for age at first calving

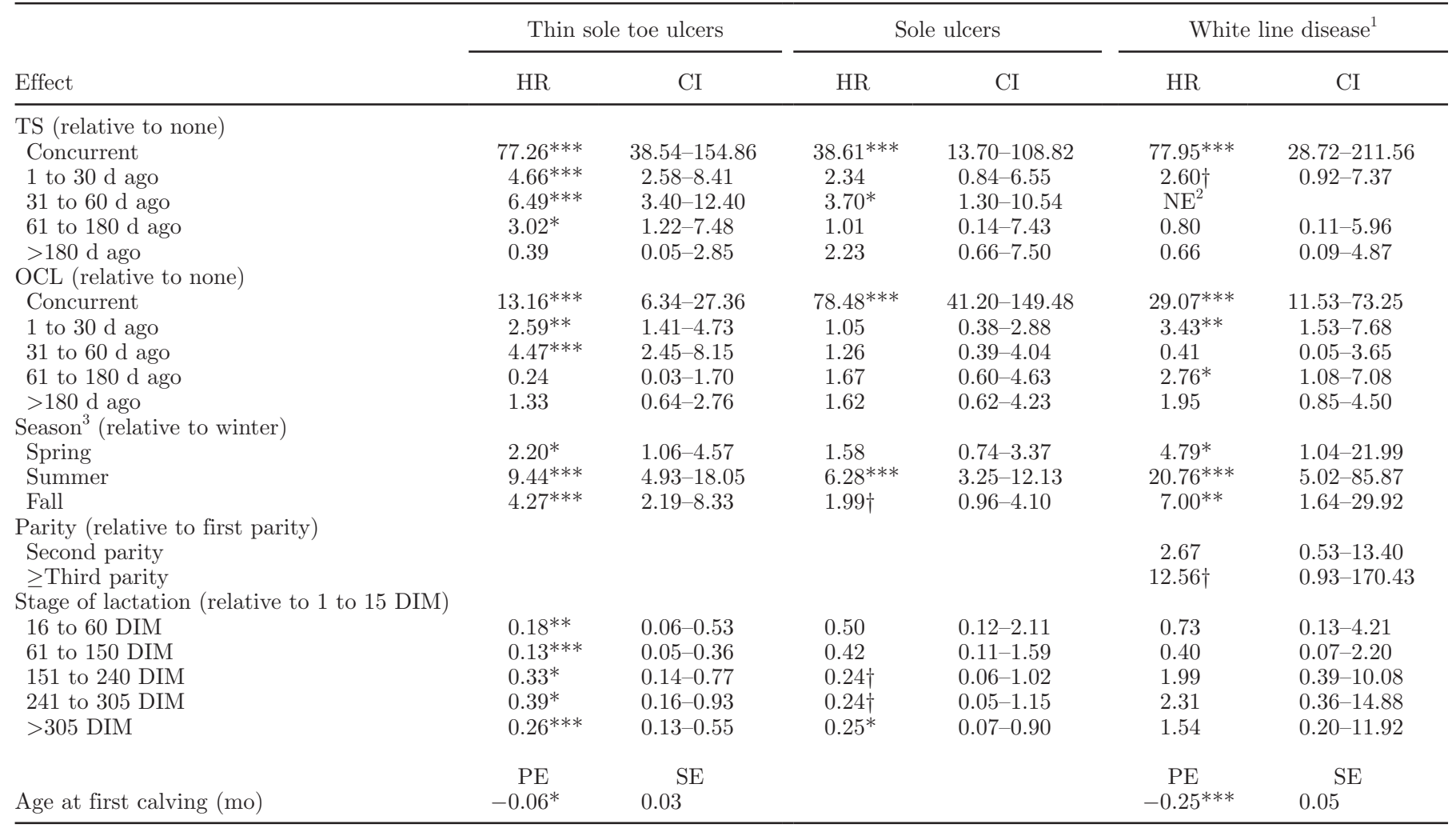

${ }^{1}$ Significant $(P>0.10)$ differences were seen between stages with the greatest and lowest hazards; thus, stage of lactation effects were kept in the final model, although no stage differed significantly from 1 to 15 DIM.

${ }^{2} \mathrm{NE}=$ nonestimable.

${ }^{3}$ Four 3-mo seasons: January through March was considered winter.

$\dagger P<0.10 ;{ }^{*} P<0.05 ;{ }^{*} P<0.01 ;{ }^{* * *} P<0.001$.

et al. (2004) also found evidence that cows with softer claws tended to have more severe lesions. The issue of concurrency is somewhat difficult to interpret because of the nature of data recording (most particularly the lack of specific claw identification and classification of the presenting versus secondary lesions).

Horn growth is minimal around the time of calving (Livesey and Laven, 2007), and lactation status influences aspects of cow time budgets associated with lameness. For example, cows spend more time standing in mid lactation than in later lactation (Nielsen et al., 2000). It is unclear why hazard for TSTU is decreased in mid lactation (61 to 150 DIM). However, unobserved lameness during the dry period may contribute to increased lameness in early lactation. Others have reported no association between stage of lactation and lameness (Warnick et al., 1995; Espejo et al., 2006) or a greater incidence of lameness earlier in lactation (Eddy and Scott, 1980; Warnick et al., 2001). In this study, stage of lactation effects were significant only for TSTU, SU, and WLD.

The effects of age at first calving were mixed, with later calving decreasing the hazard of TSTU and WLD but increasing the hazard of HU. Previous results were also mixed, with Ettema and Santos (2004) reporting a tendency for older calving heifers to have a greater incidence of lameness, but Rutherford et al.(2008) finding an association of earlier first calving with increased subsequent lameness. In both of these studies, all types of lameness were considered together.

In previous studies, higher producing cows were more likely to develop SU or WLD (Amory et al., 2008) or become lame (Barkema et al., 1994; Green et al., 2002), and lame cows may suffer production losses (Warnick et al., 2001; Green et al., 2002). These studies were able to evaluate production effects before and after lameness. In this study, we were only attempting to account for possible differences in susceptibility to lameness 
Table 7. Final multivariate Cox proportional hazards regression results for first occurrence of heel ulcers, sole punctures, and toe ulcers: hazard ratios (HR) with $95 \%$ confidence intervals (CI) for time-dependent effects [prior incidence of thin soles (TS) and other claw lesions (OCL), season, parity, and stage of lactation] and parameter estimates (PE) for age at first calving

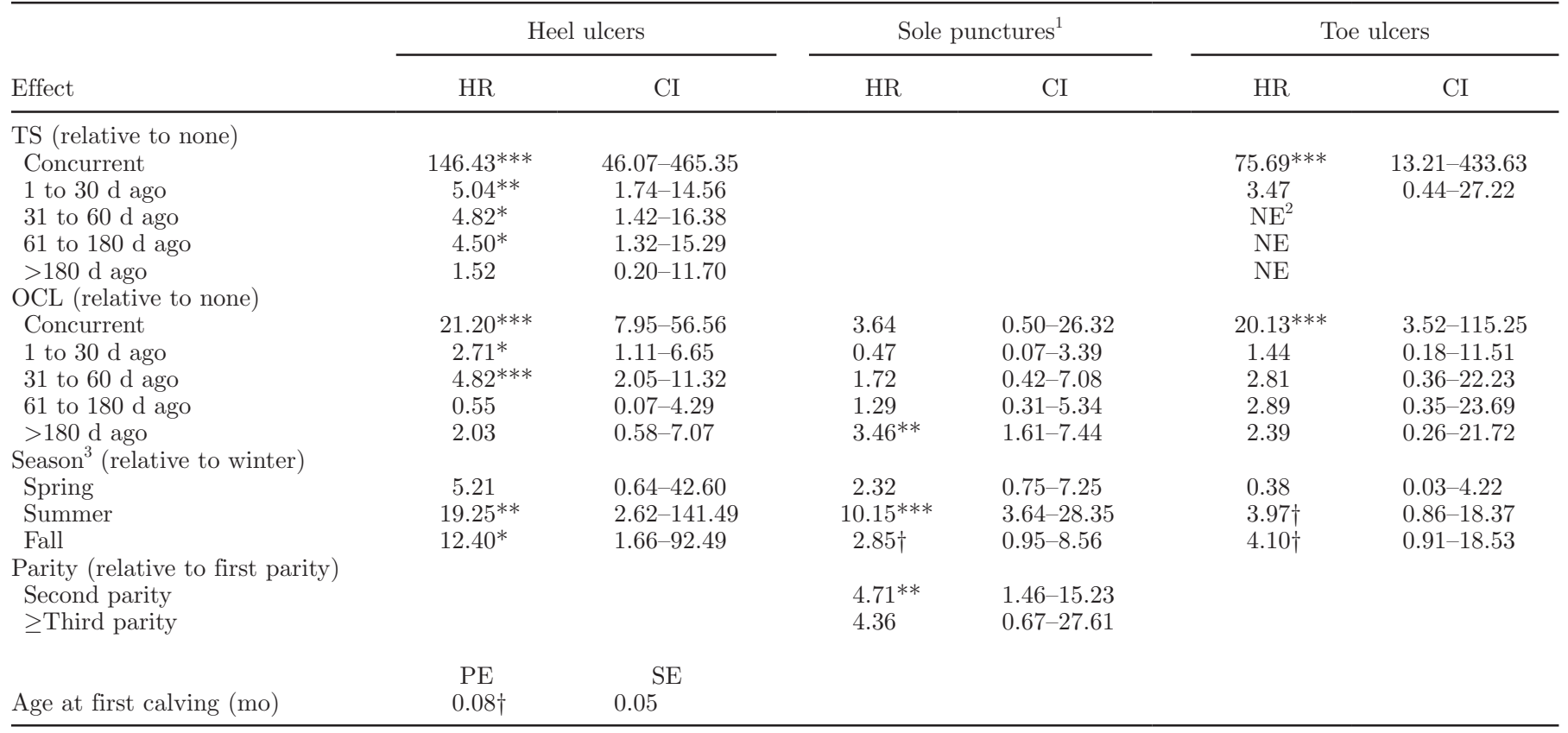

${ }^{1}$ Effect of prior TS were nonestimable for prior events 1 to $180 \mathrm{~d}$ ago and the effect of other TS events was nonsignificant $(P>0.10)$; thus, TS was not included in the final model.

${ }^{2} \mathrm{NE}=$ nonestimable.

${ }^{3}$ Four 3-mo seasons: January through March was considered winter.

$\dagger P<0.10 ;{ }^{*} P<0.05 ;{ }^{* *} P<0.01 ;{ }^{* * *} P<0.001$.

between higher and lower producing cows, without establishing causality. No associations between hazard for lameness conditions and milk production capacity were observed.

Although SP might intuitively be assumed to occur randomly, hazard for SP was highly seasonal. An association with TS could explain this seasonality, and TS might reasonably be expected to have greater susceptibility to puncture because of lower horn strength. However, no such association was seen, and the association of SP with OCL was weak.

\section{CONCLUSIONS}

A unique aspect of this study was the availability of claw lesion-specific diagnosis of lameness. Use of lifetime records allows accounting for continuous changes in claw conditions caused by wear and growth. The most common causes of lameness were TSTU and SU, followed by TS. Thin soles were a significant risk factor for TSTU and SU, and for HU. Thin sole toe ulcers are commonly misdiagnosed as WLD or TU, thereby confusing the interpretation of risk factors. All lameness conditions evaluated were most common in the summer. The most important causal factor of seasonality is probably the wet conditions created by cow-cooling systems and humidity, although other effects of heat stress may contribute. Wet conditions have been shown to increase the incidence of TS. Cows with another prior or concurrent lesion (excluding TS) were at greater risk for WLD and all types of claw ulcers. The role of TS as a contributing factor in developing other lesions, and the association of TS with specific environmental factors demonstrate the importance of considering TS as a target for lameness prevention.

\section{ACKNOWLEDGMENTS}

D. W. Webb of Southeast DHIA (Gainesville, FL) provided assistance with lactation data, and L. C. Shearer (Department of Large Animal Clinical Services, University of Florida, Gainesville) facilitated collection of the lameness records. We also thank the farm owner and the hoof trimmers who provided these unique data.

\section{REFERENCES}

Allison, P. D. 1995. Survival Analysis Using the SAS ${ }^{\circledR}$ System: A Practical Guide. SAS Institute Inc., Cary, NC.

Amory, J. R., Z. E. Barker, J. L. Wright, S. A. Mason, R. W. Blowey, and L. E. Green. 2008. Associations between sole ulcer, white line 
disease and digital dermatitis and the milk yield of 1824 dairy cows on 30 dairy cow farms in England and Wales from February 2003-November 2004. Prev. Vet. Med. 83:381-391.

Amory, J. R., P. Kloosterman, Z. E. Barker, J. L. Wright, R. W Blowey, and L. E. Green. 2006. Risk factors for reduced locomotion in dairy cattle on nineteen farms in the Netherlands. J. Dairy Sci. 89:1509-1515.

Barkema, H. W., J. D. Westrik, K. A. S. van Keulen, Y. H. Schukken, and A. Brand. 1994. The effects of lameness on reproductive performance, milk production and culling in Dutch dairy farms. Prev. Vet. Med. 20:249-259.

Booth, C. J., L. D. Warnick, Y. T. Gröhn, D. O. Maizon, C. L. Guard, and D. Janssen. 2004. Effect of lameness on culling in dairy cows. J. Dairy Sci. 87:4115-4122.

Borderas, T. F., B. Pawluczuk, A. M. de Passille, and J. Rushen. 2004 Claw hardness of dairy cows: Relationship to water content and claw lesions. J. Dairy Sci. 87:2085-2093.

Clarkson, M. J., W. B. Faull, J. W. Hughes, F. J. Manson, J. B. Merritt, R. D. Murray, J. E. Sutherst, W. R. Ward, D. Y. Downham, and W. B. Russell. 1996. Incidence and prevalence of lameness in dairy cattle. Vet. Rec. 138:563-567.

Cook, N. B. 2003. Prevalence of lameness among dairy cattle in Wisconsin as a function of housing type and stall surface. J. Am. Vet. Med. Assoc. 223:1324-1328.

Cook, N. B., T. B. Bennett, and K. V. Nordlund. 2004. Effect of free stall surface on daily activity patterns in dairy cows with relevance to lameness prevalence. J. Dairy Sci. 87:2912-2922.

Cook, N. B., R. L. Mentink, T. B. Bennett, and K. Burgi. 2007. The effect of heat stress and lameness on time budgets of lactating dairy cows. J. Dairy Sci. 90:1674-1682.

Cook, N. B., and K. V. Nordlund. 2009. The influence of the environment on dairy cow behavior, claw health and herd lameness dynamics. Vet. J. 179:360-369.

Cramer, G., K. D. Lissemore, C. L. Guard, K. E. Leslie, and D. F. Kelton. 2008. Herd- and cow-level prevalence of foot lesions in Ontario dairy cattle. J. Dairy Sci. 91:3888-3895.

Dohoo, I., W. Martin, and H. Stryhn. 2003. Measures of Disease Frequency. Pages 65-84 in Veterinary Epidemiologic Research. AVC Inc., Charlottetown, Prince Edward Island, Canada.

Eddy, R. G., and C. P. Scott. 1980. Some observations on the incidence of lameness in dairy cattle in Somerset. Vet. Rec. 106:140-144.

Espejo, L. A., M. I. Endres, and J. A. Salfer. 2006. Prevalence of lameness in high-producing Holstein cows housed in freestall barns in Minnesota. J. Dairy Sci. 89:3052-3058.

Ettema, J. F., and J. E. P. Santos. 2004. Impact of age at calving on lactation, reproduction, health, and income in first-parity Holsteins on commercial farms. J. Dairy Sci. 87:2730-2742.

Fregonesi, J. A., D. M. Veira, M. A. G. von Keyserlingk, and D. M. Weary. 2007. Effects of bedding quality on lying behavior of dairy cows. J. Dairy Sci. 90:5468-5472.

Green, L. E., V. J. Hedges, Y. H. Schukken, R. W. Blowey, and A. J. Packington. 2002. The impact of clinical lameness on the milk yield of dairy cows. J. Dairy Sci. 85:2250-2256.

Greenough. P. R., and A. D. Weaver. 1997. Lameness in Cattle. 3rd ed. W. B. Saunders Company, Philadelphia, PA.
Hernandez, J., J. K. Shearer, and D. W. Webb. 2001. Effect of lameness on the calving-to-conception interval in dairy cows. J. Am. Vet. Med. Assoc. 218:1611-1614.

Kelton, D. F., K. D. Lissemore, and R. E. Martin. 1998. Recommendations for recording and calculating the incidence of selected clinical diseases of dairy cattle. J. Dairy Sci. 81:25022509.

Kossaibati, M. A., and R. J. Esslemont. 1997. The costs of production diseases in dairy herds in England. Vet. J. 154:41-51.

Laven, R. A., and K. R. Lawrence. 2006. An evaluation of the seasonality of veterinary treatments for lameness in UK dairy cattle. J. Dairy Sci. 89:3858-3865.

Livesey, C. T., and R. A. Laven. 2007. Effects of housing and intake of methionine on the growth and wear of hoof horn and the conformation of the hooves of first-lactation Holstein heifers. Vet. Rec. 160:470-476.

Nielsen, B. L., R. F. Veerkamp, and A. B. Lawrence. 2000. Effects of genotype, feed type and lactational stage on the time budget of dairy cows. Acta Agric. Scand. A 50:272-278.

Rutherford, K. M. D., F. M. Langford, M. C. Jack, L. Sherwood, A. B. Lawrence, and M. J. Haskell. 2008. Hock injury prevalence and associated risk factors on organic and nonorganic dairy farms in the United Kingdom. J. Dairy Sci. 91:2265-2274.

SAS Institute. 2005. SAS OnlineDoc 9.1.3. SAS Institute Inc., Cary, NC.

Shearer, J., D. Anderson, W. Ayars, E. Belknap, S. Berry, C. Guard, K. Hoblet, E. Hovingh, G. Kirksey, A. Langill, A. Mills, D. Miskimins, J. Osterstock, R. Price, D. Prigel, A. Roussel, S. R. van Amstel, R. Wallace, J. Wasson, N. Cook, E. Garrett, D. Hostetler, and L. Schugel. 2004. A record keeping system for capture of lameness and foot-care information in cattle. Proc. Am. Assoc. Bovine Pract. Conf. 38:83-91.

Toussaint Raven, E. 1989. Structure and Function. Pages 24-26 in Cattle Foot Care and Claw Trimming. E. Toussaint Raven ed. Farming Press, Ipswich, UK.

van Amstel, S. R., and J. K. Shearer. 2008. Clinical report: Characterization of toe ulcers associated with thin soles in dairy cows. Bovine Pract. 42:1-8.

van Amstel, S. R., J. K. Shearer, and F. L. Palin. 2004. Moisture content, thickness, and lesions of sole horn associated with thin soles in dairy cattle. J. Dairy Sci. 87:757-763.

Warnick, L. D., H. N. Erb, and M. E. White. 1995. Lack of association between calf morbidity and subsequent first lactation milk production in 25 New York Holstein herds. J. Dairy Sci. 78:28192830 .

Warnick, L. D., D. Janssen, C. L. Guard, and Y. T. Gröhn. 2001. The effect of lameness on milk production in dairy cows. J. Dairy Sci. 84:1988-1997.

Wells, S. J., A. M. Trent, W. E. Marsh, and R. A. Robinson. 1993. Prevalence and severity of lameness in lactating dairy cows in a sample of Minnesota and Wisconsin herds. J. Am. Vet. Med. Assoc. 202:78-82. 